some cases of guinea-worm or dracunculus when visited by the author. On leaving India, he stretched across the Indian Ocean and the China Sea to Canton; here Dr. Parker's Hospital administers to the relief of great numbers of patients afflicted with cataract, ectropium, ptosis, and other diseases of the eye; tumours of enormous size are very common.

We here meet also with the small and crippled feet of the Chinese ladies, of which Dr. Berncastle gives an interesting description, and an amusing reason of a Chinese mother for insisting on her daughter's submission to this long course of pain and suffering:- "Suppose he no small foot, no man wantjee make he number one wife."

After a second short visit to "the Cape," Dr. Berncastle returned to England.

In dismissing these volumes, we do so with the conviction that, both to the medical and general reader, their perusal will while away many an hour both with amusement and instruction.

\section{Jiem Jinbentions}

IN AID OF THE

\section{PRACTICE OF MEDICINE AND SURGERY.}

Patent Esculapian Still and Condensing A pparatus. Corfex \& Smith, Providence-row, Finsbury-square.

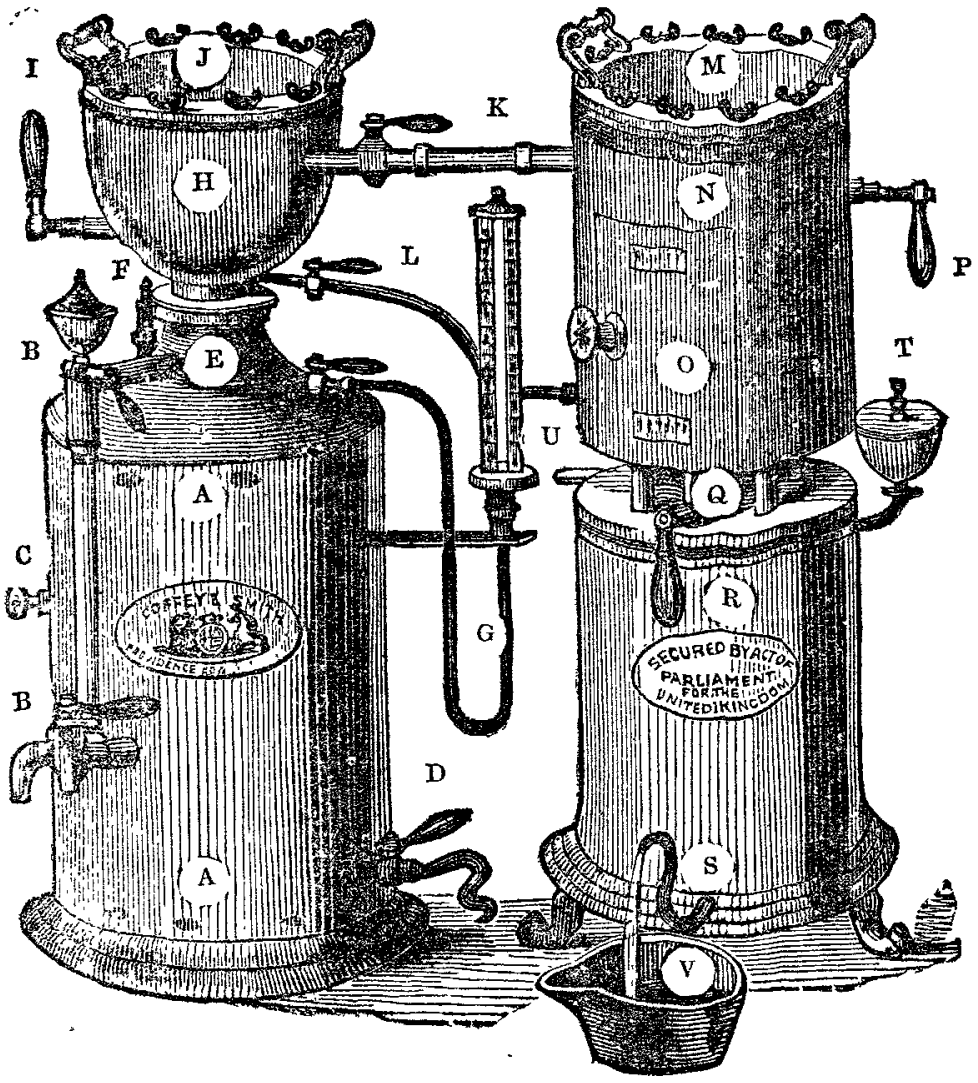

A, gas furnace, with air tube, wire ganze, pumice stone \&c, in side; B B, discharge cock from boiler, wat ar gauge, and cup for side; B B, discharge cock from bonler, water gauge, and eup for feeding boller, $C$, hande of ramace door, $D$, gas eck and flexible tube; E, neck or holler;, , safety valve and whistle; $G$, steam gauge and thermometer; H, cup-shaped head and jacket; 1 , regulating lever coniected to valve in Jacket; J, moveable pan; $K$, main steam pipe; $\mathbf{L}$, condensed steam plpe; $\mathrm{M}$, moveable jan over drying closet; $\mathrm{N}$, drying closet, door, and ventilators; $\mathrm{P}$, regtadener $R$, ves el co 1 ; $Q$, spent steam cock connected to confor distill, vestel cont $\mathrm{T}$, U, disted water; $T$, funnel and cover for flling condensing tub U, outlet

Mode of Operation.-Steam being generated in boiler by gas or other fuel, ascends through neck $(E)$ into head $(H)$, contain. ing jacket inside, so construeted that by turning handle (I) you admit or shut off steam from an orifice, in direct contact with any vessel placed therein; a moveable pan (J), block tin still retort, \&c., can be operated upon with precision and almost unparalleted superiority, as you can regulate your temperature by increasing or decreasing jet of steam, (upon pan retort, \&c.) To the right (of $\mathbf{H}$ ) near the top is a main steam pipe (K), which conducts steam to a circular chamber, the top being precisely the same as H I J (opposite), two-thirds of bottom being devoted to steam drying closet (N O) with cock below (Q), which admits spent steam into condenser, contained in circular vessel underneath $(\mathbf{R})$, which is filled with cold water (by T), and ultimately comes out (through S) as condensed steam, or distilled water. If required, one or two more worms can be added to connect to block tin still, \&c, \&c.

By means of this apparatus, the operator can perform half-adozen different processes in a few square feet, and it can be put into action, or stopped instanter at any stage of the proceedings. It not only acts as a stove, but contains a still condenser, two, three, or four evaporating and decocting pans, steam bath, (for retort), drying closet, \&c. The heat can also he regulated, with the greatest ease and safety, from $150^{\circ}$ to $250^{\circ}$, or $300^{\circ} \mathrm{Fah}$., if necessary. The apparatus, except when of very large size, is readily portable.

The advantage of an apparatus by which many different processes can be conducted at once will be readily apparent to all who are engaged in pharmaceutical operations. We are acquainted with those who are so engaged, and who have used the Esculapian still, of which they have expressed their approval. It has indeed been set forth as one of the especial recommendation of this invention, that it does not demand continuous personal attention. In a qualified sense, this may be the case, but like other fire and water machinery, it must not be left wholly to itself. On the whole, we feel warranted in recommending Messrs. Coffey and Smith's apparatus to all whom it may concern.

\section{THE UNIVERSITY OF ST. ANDREW'S AND HOMOEOPATHY. \\ To the Editor of THE LANCET.}

Srr,-As I am led to infer by your leading article in this morning's LANCET that you charge the University of St. Andrew's with having conferred the degree of doctor of medicine on a homoopathic practitioner, I must beg you to publish the accompanying extracts from the answers given by the gentleman in question, as well as a copy of the ncte which I have addressed to him on the subject of your editorial. remarks.

\section{I am, Sir, your obedient servant,}

1. Name the emetics included in the Pharmacopœia, and state the doses in which they should be prescribed.

Answer. Ipecacuanha, tartar-emetic, sulphate of zinc, and sulphate of copper. The doses are, of ipecacuanha, one scruple; of tartar-emetic, from one grain to two grains, acting better if in combination with ipecacuanha; of sulphate of zinc, from five grains to ten grains; and of sulphate of copper, from two to four or five grains.

2. Name the cases in which croton oil, aloes, jalap, gamboge, scammony, and elaterium, are specially applicable, and the form and dose in which you usually prescribe them.

Answer. Croton oil is administered in cases of very obstinate constipation, where other milder purgatives fail. It is used externally as a powerful means of counter-irritation.

Aloes is a useful purgative where there is inertia of, or accumulation of feculent matter in, the sigmoid flexure of the colon, or in the rectum, and in cases of atonic dyspepsia, chlorosis, \&c.

Jalap is a useful purgative in a variety of diseases, and is useful in cases of worms \& $c$. in children.

Gamboge and scammony are allied purgatives, the former being rather more drastic than the latter.

The dose of croton oil is usually from the one-eighth to the one-fourth of a drop, according to the strength of the patient and the urgency of the symptoms. It is seldom given uncombined, and generally in the form of pills.

Aloes are given in pills, in doses of from five to ten grainsgenerally given in combination with scammony, calomel, or blue-pill. The decoction of aloes is a useful form, the dose being from half an ounce to an ounce and a half.

Gamboge and scammony, mostly in pills. Dose, from threo to five grains of the former, and about the same of the latter. 
Elaterium is a powerful hydragogne cathartic, nseful in various forms of dropsy, in carrying off a large amount of serum from the intestinal mucous membrane. Dose, from one-sixth to one-fourth of a grain.

3. Write a Latin prescription for an expectorant mixture suitable for a case of chronic bronchitis; also for a warm aperient draught.

Answer.

B. Misturæ anmoniaci, uncias quinque.

Tincturæ scillæ, drachmas duas. opii compositæ, drachmas duas.

Misce. Fiat mistura. Capiat cochleare unum amplum bis vel ter in die.

R Decocti aloes compositi, drachmas sex. Tincturæ rhœi compositæ, drachmam.

Misturæ camphoræ, drachmas quatuor.

Fiat haustus quamprimum sumendus.

4. Describe the treatment of iritis.

Answer. Mercury is the chief remedial agent, preceded by general or local abstraction of blood, if the strength of the patient will bear it. It should be given in small, frequentlyrepeated doses-half a grain or a grain of calomel. In small doses, first, because the system is more rapidly brought under the action of mercury when the doses are small and frequently repeated; and second, because opium being contraindicated, owing to its effect in producing contraction of the pupil, it ought to be given in doses that will not irritate the intestinal mucous membrane, producing diarrhcea, by which it would be carried out of the system, and not absorbed into it. In the strumous diathesis, the mercury should be given with caution; the doses should be smaller; and the bichloride often acts better than the chloride, in such cases. In the gouty and rheumatic diathesis, colchicum may be combined with the mercurial; and iodide of potassium is advantageous in some forms of the disease.

Besides the local treatment by leeching, the external application of belladonna and the exclusion of light are most important means to prevent the closure and adhesion of the free margin of the iris.

Counter-irritation may be demanded, in addition to other treatment.

5. Describe the treatment of acute laryngitis.

Answer. The treatment consists in active antiphlogosis, bleeding, leeching, \&c.; the exhibition of mercury, (calomel, two grains, every two, three, or four hours;) but this may be preceded, in most cases, by nauseating doses of tartar-emetic, (one-sixth to one-fourth of a grain,) every two, three, or four hours. Leeches should not be applied over the larynx, owing to the difficulty of using pressure to stop the bleeding. Cupping to the nape of the neck is often better than leeches.

6. Describe the treatment of enteritis.

Ansuser. Antiphlogistic treatment here must not be so rigorous as in many other inflammatory affections, as there is a tendency to prostration. Local abstraction of blood, fomentations and poultices; the exhibition of mucilaginous drinks with the cautious exhibition of calomel or hydrargyrum c. creta, in combination with opium or Dover's powder, include the prin ciples of treatment. In this disease, the exhibition of opium alone, with other means tending to diaphoresis, will often be sufficient; and, under this treatment, the action of the bowels will become restored without the use of purgatives, which, in this disease, are questionable in any of the ordinary forms.

7. Mention the treatment of the various forms of intestinal entozoa.

Answer. For the tape-worm; the best remedy for ejecting it is the oil of turpentine, given in doses of from three draclims to five drachms, with castor oil.

The lumbrici are expelled by many purgatives, which have the effect of producing mucous stools, as calomel and jalap, scammony, \&c.

Ascarides may be got rid of by using, in addition to the above, enemata of infusion of quassia.

In all cases of worms, the tone of the digestive apparatus should be improved by tonics and alteratives.

Although the above extracts from Dr. Hale's written answers "specifying the mode of treatment he is in the habit of adopting, and the doses of the medicines which he prescribes" [see the note to our third Examination Paper], are, I think, sufficient to demonstrate that he cannot be a Homoeopath, I may add the additional evidence afforded by some portions of his oral examination in materia medica. Dr. An- derson was his examiner, but I was present, and noted down the questions and answers.

Dr. Hale stated that the doses of bichloride of mercury, when given as an alterative, varied from one-twelfth to onesixteenth of a grain; that in croup (in the case of a child of three years of age), he would give one-sixth to one-fourth of a grain of tartar-emetic every four hours; and that in the pneumonia of adults he would give half a grain of the same medicine every three or four hours; that in prescribing hyoscyamus as a sedative, he gave eight or ten grains of the extract; and, finally, that he used arsenious acid in certain forms of skin disease (the squamons forms), and in diseases of a periodic type, his dose being one-sixteenth of a grain, or from five to ten or fifteen minims of Fowler's solution.

George E. Day.

\section{Copy of Dr. Day's Note to Dr. Hale.}

Dear Sir,-There is an article in Tre Lancet of this week asserting that you have been, and still are, practising homoopathy.

As no homcopathist, without utterly denying his creed, and being guilty of the grossest deception, could have replied as you did to the practical questions, I entertain a sanguine hope that you will meet this charge with a prompt and distinct denial.

In order at once to check a report equally injurious to yourself, and to the University from which you have received your degree, I forward by this post to THe LANCET certain extracts from your answers to the practical questions, and a copy of the note $I$ have now the honour of addressing you.

Dr. Robert Douglas Hale. I am, dear sir, faithfully yours,

George E. Day.

\section{To the Editor of The Lancet.}

SrR,-My name has been wantonly introduced in your journal: and I am represented as not having acted the part of an honest and conscientious man.

My written answers to the questions put, at the May examination at St. Andrew's, to the candidates for the degree of M.D., will show, if they have been kept, that they were such as any honest and conscientious man might have written.

For my professional attainments the University was my judge, not you: for the application of therapeutics $I$ am responsible to my patients, to my own conscience, and to God, and not to you, or to any man, or to any body of men.

My conduct and character will bear scrutiny, and $I$ shall be glad to assist you in any investigation you may choose to institute in your tyrannous assumption of medical dictatorship, which, however, the liberal members of a liberal profession repudiate, as does

Norwich, June 10, 1851.

Your obedient servant, Robt. Dodglas Hale.

** We shall await with some interest the further pro. ceedings of the University of St. Andrew's. The above letter scarcely requires notice, its evasions are so obvious.-ED. I.

Royal College of Surgeons. - The President and Council of this institution gave one of their evening's entertainments, on Wednesday last, to their members and other distinguished members of the profession. The company, who began to arrive at eight o'clock, were received in the magnificent library, where some of Mr. Gould's superb ornithological plates were exhibited, together with the microscopical preparations, of which the College possess an unrivalled collection, principally prepared by the late Mr. Hewson, and Dr. Todd, of Brighton; together with the more recent and brilliant pre. parations of Mr. Quekett, who, with the microscopes, entertained a large portion of the visitors. Mr. Stone alsp exhibited his collection of medical portraits and autographs, which has been greatly increased hy the valuable purchases made at the sale of the effects of the late Mr. Clift, so long and so intimately connected with the immortal Hunter. At nine o'clock Professor Owen delivered an elaborate lecture on Metamor phosis and Metegenesis, to a crowded audience. Among the distinguished visitors present we observed the venerable Archdeacon Hale, Drs. Paris, Copland, Nairne, and Messrs. Arnott, South, Hawkins, Lawrence, Guthrie, Sir J. Droatt, Sir B. Brodie, \&c. \&c. About 450 gentlemen were present, a large number of whom expressed their great satisfaction at these interesting re-unions. 